\title{
Dietary Sodium Intake Is Positively Associated with Sugar-Sweetened Beverage Consumption in Chinese Children and Adolescents
}

\author{
Zhenni Zhu ${ }^{1, *}\left(\mathbb{D}\right.$, Xueying Cui ${ }^{1}$, Xiaohui Wei ${ }^{2}$, Jiajie Zang ${ }^{1}$, Jingyuan Feng ${ }^{2}$, Zhengyuan Wang ${ }^{1}$ and Zehuan Shi ${ }^{1}$ \\ 1 Division of Health Risk Factors Monitoring and Control, Shanghai Municipal Center for Disease Control and \\ Prevention, 1380 West Zhongshan Road, Shanghai 200036, China; cuixueying@scdc.sh.cn (X.C.); \\ zangjiajie@scdc.sh.cn (J.Z.); wangzhengyuan@scdc.sh.cn (Z.W.); shizehuan@scdc.sh.cn (Z.S.) \\ 2 School of Public Health, Fudan University, 130 Dongan Road, Shanghai 200030, China; \\ xhwei16@fudan.edu.cn (X.W.); jyfeng16@fudan.edu.cn (J.F.) \\ * Correspondence: zhuzhenni@scdc.sh.cn; Tel.: +86-21-62758710
}

check for updates

Citation: Zhu, Z.; Cui, X.; Wei, X.; Zang, J.; Feng, J.; Wang, Z.; Shi, Z. Dietary Sodium Intake Is Positively Associated with Sugar-Sweetened Beverage Consumption in Chinese Children and Adolescents. Nutrients 2021, 13, 3949. https://doi.org/ 10.3390/nu13113949

Academic Editor: Xinyin Jiang, Gangqiang Ding and Liang Wang

Received: 14 October 2021 Accepted: 3 November 2021 Published: 5 November 2021

Publisher's Note: MDPI stays neutral with regard to jurisdictional claims in published maps and institutional affiliations.

Copyright: (c) 2021 by the authors. Licensee MDPI, Basel, Switzerland. This article is an open access article distributed under the terms and conditions of the Creative Commons Attribution (CC BY) license (https:// creativecommons.org/licenses/by/ $4.0 /)$.

\begin{abstract}
Sugar-sweetened beverage (SSB) consumption among children and adolescents is steadily increasing in China, while the main taste of Chinese food is salty. The present study aimed to determine the relationships between SSB and total fluid consumption and dietary sodium and salt intake among children and adolescents in China. The data were obtained from a cross-sectional investigation in 2015. A total of 3958 participants were included. A 24-h dietary record for three consecutive days was collected to determine the SSB intake and food consumption across school days and rest days. After adjusting for age, sex, yearly household income, maternal education, intentional physical exercise, and instances of eating out in the last week, the dietary sodium intake was positively associated with the SSB consumption $(p<0.05)$, but salt was not. After stratifying by sex, grades, and puberty status, the associations between dietary sodium intake and SSB consumption were significant in girls, in grades $1-5$ and before puberty $(p<0.05)$. Dietary sodium intake was positively associated with SSB consumption in Chinese children and adolescents, particularly in young children. A reduction of the sodium intake might help reduce SSB consumption among children and adolescents.
\end{abstract}

Keywords: sugar-sweetened beverage; dietary sodium; salt; total fluid; association

\section{Introduction}

As the dietary pattern of Chinese people has been dramatically Westernized in the past two decades, SSB consumption among children and adolescents has steadily increased [1]. The consumption of sugar-sweetened beverages (SSBs) among children and adolescents is becoming a public health concern due to its adverse effects [2,3]. Excessive SSB consumption has been shown to closely correlate with a higher risk of obesity [4], type-2 diabetes [5], cardiometabolic health [6], and dental caries [7] in children and adolescents. These then contribute to an increased risk of consequent health problems in adulthood [8].

The main taste of Chinese food is salty; accordingly, Chinese people consume a considerable amount of sodium, amounting to more than twice the recommended consumption set by WHO $[9,10]$. The main sources of dietary sodium in Chinese food are salt, soy sauce, processed food, and monosodium glutamate [11,12]. Overconsumption of dietary sodium is a major risk factor related to elevated blood pressure in children and adolescents, which may, in turn, accelerate the development of hypertension over their whole life course [13].

Excessive dietary sodium intake prompts thirst, which might drive increased consumption of SSBs [14,15]. Indeed, it has been reported that high dietary sodium intake is associated with high consumption of SSBs and increased total fluids needed in children $[16,17]$. Both SSBs and dietary sodium are risk factors to children's health, and their negative effects could be compounded by an association between the two. Since dietary 
sodium intake is generally excessive and SSB consumption has markedly increased recently in China [18], the two could pose double threats to the health of Chinese children. However, little is known about the correlation between SSB consumption and dietary sodium or salt intake among Chinese children and adolescents. Therefore, we performed the present study to determine the relationship between SSB and total fluid consumption and dietary sodium or salt intake among children and adolescents in China.

\section{Materials and Methods}

\subsection{Study Population}

The data in this study were obtained from a cross-sectional investigation that was conducted from September to October 2015 as a part of the Shanghai Diet and Health Survey (SDHS), which was conducted in Shanghai, one of the most developed cities in China. The SDHS was designed to examine the associations of food consumption, energy and nutrient intake, and behavioral factors with nutrition-related health outcomes among local residents. In 2015, a random representative sample of local children aged 6-17 years old who attended school were selected through a multistage stratified sampling method from 20 primary, 20 junior high and 20 senior high (or equivalent secondary vocational) schools $(n=4320)$. The participants who failed to complete either part of the questionnaire survey $(n=237)$, missed anthropometric measurements $(n=78)$, or refused to provide a blood sample $(n=47)$ were excluded. The data from 3958 participants were included in the present analysis. The 2015 SDHS was approved by the Shanghai Municipal Center for Disease Control and Prevention's Institutional Review Board on 2 September 2015 (no. 2015-15). Written informed consent was obtained from each participant or the participant's parents or guardians before the survey. The study complied with the code of ethics of the World Medical Association (Declaration of Helsinki) [19].

\subsection{Dietary Intake}

SSBs were defined as nonalcoholic beverages sweetened by sugar, excluding fresh juice. Since the serving sizes of beverages vary in China-for example, a 1.5-L bottle of a drink is a common size and is usually shared by several persons or consumed over several separate occasions-a 24-h dietary record for three consecutive days (including two weekdays and one weekend day) was collected to determine the SSB intake and food consumption across school days and rest days. Each participant was orally instructed to record their daily food intake (including fluid) both at school and home at the beginning and then interviewed face-to-face by interviewers in the consecutive survey days at home. At each survey day, the interviewers collected and checked though the paper, and afterward, revised the food weight and transcribed the draft dietary information into a structured form. Household condiments mainly containing fat or sodium, including cooking oil, salt, soy sauce, and chili sauce, were weighed before and after the three survey days in the same containers. The intake of dietary sodium was estimated according to daily food and condiments consumption using the Chinese food composition database [20,21]. The total fluid intake included all sources of fluid consumed either as a beverage or water in the meal. An SSB non-consumer was defined as someone who reported no SSB intake during the three-day survey period (two weekdays and one weekend day).

Furthermore, the participants were instructed not to change their typical diet or physical activity during the survey period. Their diet records were reviewed by nutrition specialists from local centers of disease control and prevention. The parents or caregivers were interviewed together with the participants who were under 12 years old. No disastrous events, such as heavy rain or snow, affected the normal food supply during the survey period. The weather from approximately September to October 2015 in Shanghai was the typical marine climate of autumn, and the temperature fluctuated within $18-30{ }^{\circ} \mathrm{C}$ or $64-86^{\circ} \mathrm{F}$. 


\subsection{Potential Confounders}

An individual's daily food and condiment consumption was calculated from the diet record and household condiment weighing. Information on each participant's age, school grade, sex, pubertal stage, household income, intentional physical exercise, instances of eating out last week, and maternal education were recorded using an interviewer-administered questionnaire at each participant's home. The pubertal stage was self-reported by the participants based on menstruation or spermatorrhea. The maternal education level of the participants was reported as years of education. Intentional physical exercise was defined as the physical exercise performed for the purpose of health maintenance or fitness. The household income was the family's total yearly income (CNY).

\subsection{Statistical Analyses}

Statistical analyses were conducted using the SAS statistical software (v. 9.2; SAS Institute, Cary, NC, USA). The Chi-squared test was applied to determine the differences in the participants' characteristics. Multivariate linear models were applied to determine the partial correlation coefficients ( $\beta$ ) and $95 \%$ confidence intervals (CIs) of the differences in participants' SSB or total fluid consumption versus their dietary salt or sodium intake. Potential confounders-including age, sex, pubertal stage, household income, intentional physical exercise, instances of eating out last week, and maternal education-were introduced as covariates in three different adjusted models. A two-sided $p<0.05$ was considered to indicate statistical significance.

\section{Results}

\subsection{Characteristics of the Participants}

The final analysis included 3955 participants, consisting of $49.7 \%$ boys and $50.3 \%$ girls. Of those, 1373 participants consumed SSBs. The proportions of the participants in grades $1-5,6-9$, and $10-12$ were $41.3 \%, 34.5 \%$, and $24.2 \%$, respectively. The percentages of SSB non-consumers and consumers in grades $1-5$ were $44.6 \%$ and $35.1 \%$, respectively (Table 1 ).

Table 1. Characteristics of the participants.

\begin{tabular}{|c|c|c|c|c|}
\hline & \multirow[b]{2}{*}{ All } & \multicolumn{2}{|c|}{ SSB Intake } & \multirow{2}{*}{$p$} \\
\hline & & Non-Consumers ${ }^{a}$ & Consumers & \\
\hline $\mathrm{N}(\%)$ & $3955(100.0)$ & $2582(65.3)$ & $1373(34.7)$ & \\
\hline Sex, $\%$ & & & & 0.375 \\
\hline Boys & 49.7 & 49.2 & 50.6 & \\
\hline Girls & 50.3 & 50.9 & 49.4 & \\
\hline Grade, \% & & & & $<0.001$ \\
\hline $1-5(6-10 y)$ & 41.3 & 44.6 & 35.1 & \\
\hline $6-9(11-14 y)$ & 34.5 & 35.3 & 33.1 & \\
\hline $10-12(15-17 \mathrm{y})$ & 24.2 & 20.1 & 31.8 & \\
\hline Entered puberty, \% & & & & $<0.001$ \\
\hline Entered puberty & 37.0 & 33.6 & 43.4 & \\
\hline Not entered puberty & 63.0 & 66.4 & 56.6 & \\
\hline Yearly household income, \% & & & & 0.201 \\
\hline Above average ( $>60,000 \mathrm{CNY})$ & 33.2 & 33 & 33.6 & \\
\hline Average $(30,000-59,999 \mathrm{CNY})$ & 23.9 & 24.1 & 23.4 & \\
\hline Below average $(<30,000 \mathrm{CNY})$ & 21.8 & 22.6 & 20.3 & \\
\hline No answer & 21.1 & 20.3 & 22.7 & \\
\hline Intentional physical exercise, $\%$ & & & & 0.819 \\
\hline No & 46.6 & 46.7 & 46.3 & \\
\hline Yes & 53.5 & 53.3 & 53.7 & \\
\hline Instances of eating out last week, $\%$ & & & & $<0.001$ \\
\hline 0 & 57 & 60.6 & 50.3 & \\
\hline $1-2$ & 25.1 & 23.7 & 27.8 & \\
\hline$\geq 3$ & 17.9 & 15.8 & 21.9 & \\
\hline Maternal education, year (SD) & $11.8(4.0)$ & $11.8(4.0)$ & $12.0(4.0)$ & 0.115 \\
\hline Dietary salt, g/d (SD) & $6.4(4.1)$ & $6.2(3.9)$ & $6.7(4.4)$ & $<0.001$ \\
\hline Dietary sodium, mg/d (SD) & $4297.6(2285.5)$ & $4160.9(2267.2)$ & $4554.5(2298.4)$ & $<0.001$ \\
\hline Dietary sodium equivalent to salt, g/d (SD) & $11(5.9)$ & $10.7(5.8)$ & $11.7(5.9)$ & $<0.001$ \\
\hline SSB consumption, g/d (SD) & $59.4(126.3)$ & $0.0(0.0)$ & $171.1(163.8)$ & $<0.001$ \\
\hline Total fluid consumption, g/d (SD) & $750(428.3)$ & $708.5(403.9)$ & $827.7(460.8)$ & $<0.001$ \\
\hline
\end{tabular}

${ }^{a}$ In this study, a non-consumer was defined as someone who reported no SSB intake during the three-day survey period (two weekdays and one weekend day). 


\subsection{The Dietary Sources of Sodium and the Correlation between Dietary Salt and Sodium}

The leading dietary source of sodium, salt, accounted for $57.4 \%$ of the total sodium intake. The following significant sources were soy sauce (13.2\%), fungi and algae (6.5\%), and monosodium glutamate (4.6\%; Figure 1$)$.

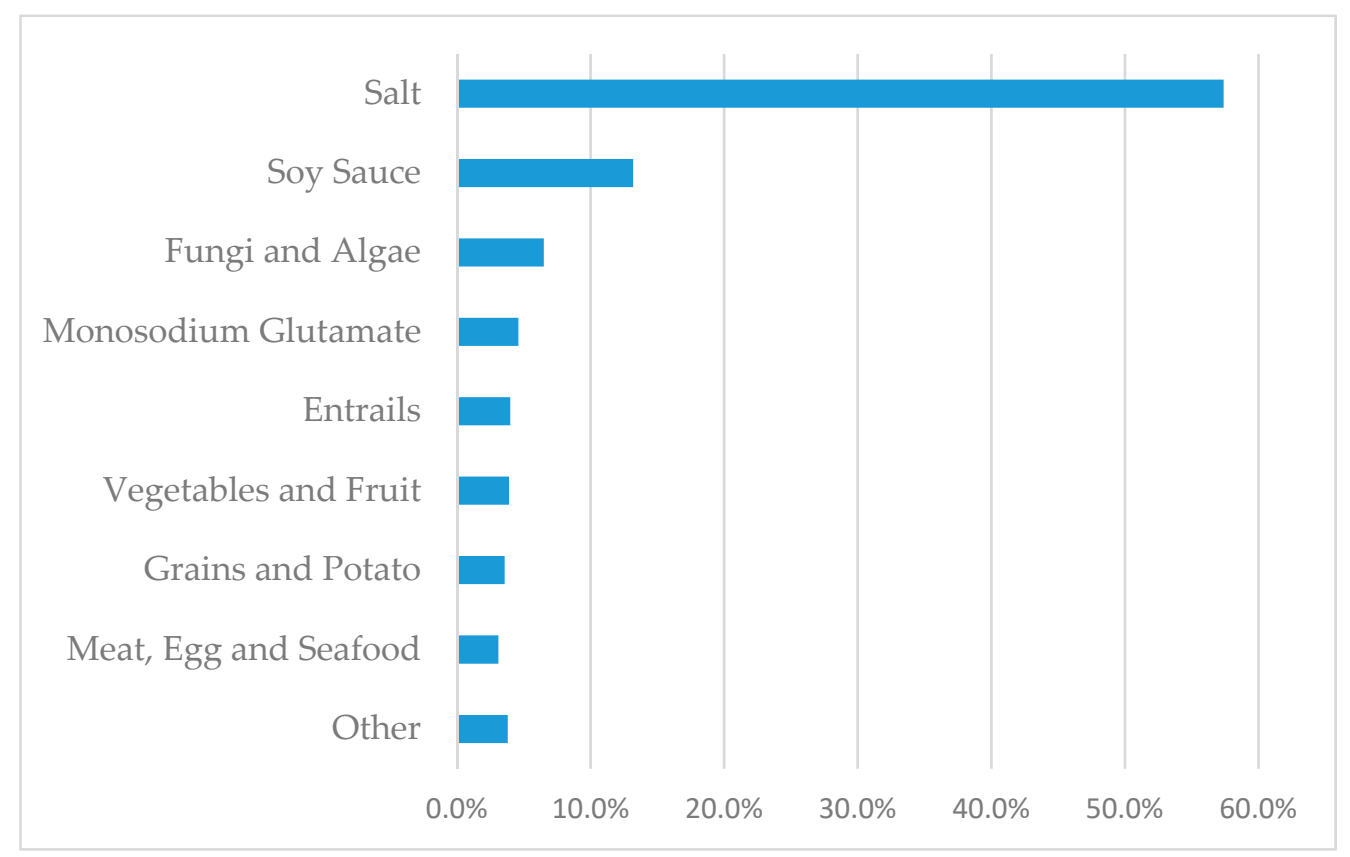

Figure 1. Dietary sources of sodium among 3958 participants from SDHS in 2015.

After adjusting for age and sex, a significant partial correlation was determined between dietary salt and sodium $(0.881, p<0.05$; Table 2$)$.

Table 2. Partial correlation coefficient between dietary sodium and salt.

\begin{tabular}{ccc} 
& Dietary Sodium & Dietary Salt \\
\hline Dietary sodium & 1 & $0.881^{\text {a }}$ \\
Dietary salt & & 1 \\
\hline a represents $p<0.05$. Adjusted by age and sex. &
\end{tabular}

\subsection{The Association between Dietary Sodium/Salt Intake and SSB Consumption}

After adjusting for age, sex, yearly household income, maternal education, intentional physical exercise, and instances of eating out in the last week (Model 3), dietary sodium was positively associated with SSB consumption $(p<0.05)$. With each additional $390 \mathrm{mg}$ of dietary sodium per day, the SSB consumption increased by $1.7 \mathrm{~g} \mathrm{(95 \%} \mathrm{CI,} 0.30-3.10)$ per day. After stratifying by sex, school grade, and puberty status, the association between dietary sodium intake and SSB consumption was still significant in girls, those in grades $1-5$, and those before puberty $(p<0.05)$. With each additional $390 \mathrm{mg}$ of salt intake per day, the SSB consumption increased by $2.7 \mathrm{~g}$ (95\% CI, 0.99-4.4), $3.5 \mathrm{~g}$ (95\% CI, 1.49-5.49), and $1.8 \mathrm{~g} \mathrm{(95 \%} \mathrm{CI,} \mathrm{0.03-3.60)} \mathrm{per} \mathrm{day,} \mathrm{respectively.}$

After adjusting for age, sex, yearly household income, maternal education, intentional physical exercise, and instances of eating out in the last week (Model 3), there was no association between salt intake and SSB consumption. When looking at specific groups within the overall study population, however, we observed a significant association between salt intake and SSB consumption among participants in grades $1-5$ and before puberty $(p<0.05)$. For children in grades $1-5$, with each additional $1 \mathrm{~g}$ of salt intake per day, the SSB consumption increased by $5.4 \mathrm{~g}(95 \% \mathrm{CI}, 2.71-8.17)$ per day. For the children before puberty, with each additional $1 \mathrm{~g}$ of salt intake per day, the SSB consumption increased by $3.0 \mathrm{~g}$ 
(95\% CI, 0.62-5.35) per day. For the different sexes, there were no significant associations between salt intake and SSB consumption (Table 3).

Table 3. Multiple linear regression analysis of SSB consumption (g/d) and dietary sodium intake (390 mg/d)/salt intake $(1 \mathrm{~g} / \mathrm{d})$ among the SSB consumers ${ }^{\mathrm{a}, \mathrm{b}}$.

\begin{tabular}{|c|c|c|c|c|c|c|c|}
\hline & & \multicolumn{3}{|c|}{ Sodium } & \multicolumn{3}{|c|}{ Salt } \\
\hline & & $\beta$ & $95 \% \mathrm{CI}$ & $p$ & $\beta$ & $95 \% \mathrm{CI}$ & $p$ \\
\hline \multicolumn{8}{|c|}{ SSB consumers $(n=1373)$} \\
\hline Model $1^{\mathrm{c}}$ & & 2.13 & $(0.67,3.59)$ & 0.004 & 1.25 & $(-0.72,3.24)$ & 0.213 \\
\hline Model $2^{c}$ & & 1.69 & $(0.29,3.09)$ & 0.018 & 0.93 & $(-0.97,2.84)$ & 0.336 \\
\hline Model $3^{c}$ & & 1.70 & $(0.30,3.10)$ & 0.017 & 0.86 & $(-1.04,2.77)$ & 0.373 \\
\hline \multicolumn{8}{|c|}{ Stratified by grades } \\
\hline & Grade $1-5$ (6-10 y) & 3.67 & $(1.74,5.57)$ & $<0.001$ & 5.53 & $(2.96,8.09)$ & $<0.001$ \\
\hline \multirow{3}{*}{ Model 1} & Grade 6-9 (11-14 y) & 1.32 & $(-1.11,3.74)$ & 0.287 & -0.20 & $(-3.32,2.93)$ & 0.902 \\
\hline & Grade $10-12$ (15-17 y) & 2.29 & $(-0.83,5.42)$ & 0.149 & 0.42 & $(-4.06,4.91)$ & 0.853 \\
\hline & Grade $1-5$ (6-10 y) & 3.49 & $(1.49,5.48)$ & $<0.001$ & 5.44 & $(2.71,8.16)$ & $<0.001$ \\
\hline \multirow[t]{3}{*}{ Model 2} & Grade 6-9 (11-14 y) & 1.15 & $(-1.15,3.45)$ & 0.325 & -0.17 & $(-3.13,2.80)$ & 0.913 \\
\hline & Grade $10-12$ (15-17 y) & 1.27 & $(-1.76,4.30)$ & 0.410 & -0.87 & $(-5.23,3.49)$ & 0.696 \\
\hline & Grade 1-5 (6-10y) & 3.49 & $(1.49,5.49)$ & $<0.001$ & 5.44 & $(2.71,8.17)$ & $<0.001$ \\
\hline \multirow[t]{2}{*}{ Model 3} & Grade 6-9 (11-14 y) & 1.00 & $(-1.29,3.30)$ & 0.390 & -0.42 & $(-3.38,2.54)$ & 0.781 \\
\hline & Grade $10-12(15-17$ y) & 1.17 & $(-1.88,4.22)$ & 0.451 & -1.27 & $(-5.63,3.09)$ & 0.567 \\
\hline \multicolumn{8}{|c|}{ Stratified by puberty status } \\
\hline \multirow{2}{*}{ Model 1} & Entered puberty & 1.43 & $(-0.86,3.73)$ & 0.220 & -1.09 & $(-4.24,2.06)$ & 0.498 \\
\hline & Not entered puberty & 2.51 & $(0.57,4.45)$ & 0.011 & 3.40 & $(0.86,5.94)$ & 0.009 \\
\hline \multirow{2}{*}{ Model 2} & Entered puberty & 1.51 & $(-0.76,3.78)$ & 0.193 & -0.77 & $(-3.89,2.35)$ & 0.629 \\
\hline & Not entered puberty & 1.78 & $(-0.01,3.57)$ & 0.051 & 2.98 & $(0.61,5.34)$ & 0.014 \\
\hline \multirow{3}{*}{ Model 3} & Entered puberty & 1.50 & $(-0.78,3.78)$ & 0.196 & -0.90 & $(-4.04,2.23)$ & 0.572 \\
\hline & Not entered puberty & 1.81 & $(0.03,3.60)$ & 0.047 & 2.98 & $(0.62,5.35)$ & 0.014 \\
\hline & \multicolumn{7}{|c|}{ Stratified by sex } \\
\hline \multirow{2}{*}{ Model 1} & Boys & 1.24 & $(-1.08,3.57)$ & 0.295 & 0.13 & $(-2.91,3.16)$ & 0.935 \\
\hline & Girls & 2.80 & $(1.05,4.55)$ & 0.002 & 2.33 & $(-0.14,4.81)$ & 0.065 \\
\hline \multirow{2}{*}{ Model 2} & Boys & 0.52 & $(-1.69,2.73)$ & 0.644 & -0.43 & $(-3.33,2.46)$ & 0.768 \\
\hline & Girls & 2.65 & $(0.94,4.36)$ & 0.002 & 2.33 & $(-0.10,4.76)$ & 0.060 \\
\hline \multirow{2}{*}{ Model 3} & Boys & 0.57 & $(-1.64,2.79)$ & 0.610 & -0.52 & $(-3.41,2.37)$ & 0.726 \\
\hline & Girls & 2.69 & $(0.99,4.40)$ & 0.002 & 2.31 & $(-0.12,4.74)$ & 0.062 \\
\hline
\end{tabular}

${ }^{a}$ In all models, the SSB consumption was treated as the independent variable and the sodium or salt intake was treated as the dependent variable. ${ }^{b} \beta$ represents the partial correlation coefficients in the models, which means the amount of SSB consumed for each additional $390 \mathrm{mg}$ sodium or $1 \mathrm{~g}$ salt intake. ${ }^{\mathrm{C}}$ Model 1: Adjusted by age and sex; Model 2: Model 1 further adjusted by yearly household income (categorical variable) and maternal education (continuous variable); Model 3: Model 2 further adjusted by intentional physical exercise (categorical variable) and number of instances of eating out last week (categorical variable).

\subsection{The Association between Dietary Sodium/Salt Intake and Total Fluid Consumption}

After adjusting for the age, sex, yearly household income, maternal education, intentional physical exercise, and instances of eating out in the last week (Model 3), no significant association of dietary sodium intake was found with total fluid consumption in the overall sample. After stratifying by grades, however, significant associations were shown for participants of grades 10-12 $(p<0.05)$; with each additional $390 \mathrm{mg}$ of dietary total sodium per day, their total fluid consumption decreased by $4.8 \mathrm{~g}(95 \% \mathrm{CI},-8.98$ to $-0.59)$ per day.

After adjusting for the age, sex, yearly household income, maternal education, intentional physical exercise, and instances of eating out in the last week (Model 3), the salt intake was negatively associated with the total fluid consumption $(p<0.05)$. With each additional $1 \mathrm{~g}$ of salt intake per day, the total fluid consumption decreased by $4.1 \mathrm{~g}(95 \%$ $\mathrm{CI},-7.36$ to -0.78$)$ per day. After stratifying by sex, school grade, and puberty status, the same associations between the salt intake and total fluid consumption were still significant in boys, participants in grades $10-12$, and those who had entered puberty $(p<0.05)$. With each additional $1 \mathrm{~g}$ of salt intake per day, the total fluid consumption decreased by $7.8 \mathrm{~g}$ (95\% CI, -12.72 to -2.81$)$, $9.6 \mathrm{~g}(95 \% \mathrm{CI},-16.31$ to -2.81$)$, and $7.7 \mathrm{~g}(95 \% \mathrm{CI},-13.23$ to -2.18 ) per day, respectively (Table 4 ). 
Table 4. Multiple linear regression analysis of total fluid consumption (g/d) and dietary sodium intake (390 mg/d)/salt intake $(1 \mathrm{~g} / \mathrm{d})$ among all participants ${ }^{\mathrm{a}, \mathrm{b}}$.

\begin{tabular}{|c|c|c|c|c|c|c|c|}
\hline & & \multicolumn{3}{|c|}{ Sodium } & \multicolumn{3}{|c|}{ Salt } \\
\hline & & $\beta$ & $95 \% \mathrm{CI}$ & $p$ & $\beta$ & $95 \%$ CI & $p$ \\
\hline \multicolumn{8}{|c|}{ All $(n=3955)$} \\
\hline Model $1^{c}$ & & -0.20 & $(-2.45,2.05)$ & 0.859 & -4.92 & $(-8.17,-1.67)$ & 0.003 \\
\hline Model $2^{c}$ & & -0.51 & $(-2.79,1.76)$ & 0.659 & -4.01 & $(-7.30,-0.72)$ & 0.017 \\
\hline Model $3^{c}$ & & -0.47 & $(-2.74,1.81)$ & 0.688 & -4.07 & $(-7.36,-0.78)$ & 0.015 \\
\hline \multicolumn{8}{|c|}{ Stratified by grades } \\
\hline \multirow{3}{*}{ Model 1} & Grade 1-5 (6-10 y) & 2.49 & $(-0.98,5.95)$ & 0.160 & -2.11 & $(-6.81,2.59)$ & 0.379 \\
\hline & Grade 6-9 (11-14 y) & 1.27 & $(-3.02,5.57)$ & 0.560 & -1.72 & $(-7.49,4.04)$ & 0.557 \\
\hline & Grade $10-12$ (15-17 y) & -3.56 & $(-7.71,0.58)$ & 0.092 & -8.93 & $\begin{array}{l}(-15.66 \\
-2.21)\end{array}$ & 0.009 \\
\hline \multirow{3}{*}{ Model 2} & Grade $1-5(6-10$ y) & 3.65 & $(0.07,7.24)$ & 0.046 & -0.33 & $(-5.27,4.61)$ & 0.895 \\
\hline & Grade 6-9 (11-14 y) & 1.62 & $(-2.75,5.99)$ & 0.467 & -0.80 & $(-6.67,5.08)$ & 0.791 \\
\hline & Grade 10-12 (15-17 y) & -4.93 & $(-9.12,-0.74)$ & 0.021 & -9.52 & $\begin{array}{l}(-16.27 \\
-2.76)\end{array}$ & 0.006 \\
\hline \multirow{3}{*}{ Model 3} & Grade $1-5(6-10 y)$ & 3.53 & $(-0.06,7.12)$ & 0.054 & -0.49 & $(-5.43,4.44)$ & 0.844 \\
\hline & Grade 6-9 (11-14 y) & 1.47 & $(-2.91,5.86)$ & 0.510 & -0.98 & $(-6.86,4.91)$ & 0.745 \\
\hline & Grade 10-12 (15-17 y) & -4.78 & $(-8.98,-0.59)$ & 0.026 & -9.56 & $\begin{array}{l}(-16.31 \\
-2.81)\end{array}$ & 0.006 \\
\hline \multicolumn{8}{|c|}{ Stratified by puberty status } \\
\hline \multirow{2}{*}{ Model 1} & Entered puberty & -2.10 & $(-5.71,1.51)$ & 0.254 & -8.16 & $\begin{array}{l}(-13.66 \\
-2.67)\end{array}$ & 0.004 \\
\hline & Not entered puberty & 0.72 & $(-2.22,3.66)$ & 0.631 & -3.15 & $(-7.18,0.87)$ & 0.124 \\
\hline \multirow{2}{*}{ Model 2} & Entered puberty & -3.18 & $(-6.83,0.48)$ & 0.089 & -7.57 & $\begin{array}{l}(-13.10 \\
-2.04)\end{array}$ & 0.007 \\
\hline & Not entered puberty & 1.15 & $(-1.82,4.13)$ & 0.447 & -1.79 & $(-5.90,2.32)$ & 0.393 \\
\hline \multirow{2}{*}{ Model 3} & Entered puberty & -3.02 & $(-6.68,0.64)$ & 0.105 & -7.70 & $\begin{array}{l}(-13.23 \\
-218)\end{array}$ & 0.006 \\
\hline & $\begin{array}{l}\text { Not entered puberty } \\
\text { ified by sex }\end{array}$ & 1.10 & $(-1.87,4.08)$ & 0.468 & -1.85 & $(-5.96,2.26)$ & 0.377 \\
\hline \multirow{2}{*}{ Model 1} & Boys & -2.09 & $(-5.56,1.39)$ & 0.239 & -8.22 & $\begin{array}{l}(-13.12 \\
-3.31)\end{array}$ & 0.001 \\
\hline & Girls & 1.09 & $(-1.77,3.95)$ & 0.454 & -2.21 & $(-6.44,2.02)$ & 0.305 \\
\hline \multirow{2}{*}{ Model 2} & Boys & -2.99 & $(-6.49,0.51)$ & 0.094 & -7.72 & $\begin{array}{l}(-12.68 \\
-2.76)\end{array}$ & 0.002 \\
\hline & Girls & 1.25 & $(-1.67,4.18)$ & 0.400 & -0.91 & $(-5.20,3.39)$ & 0.679 \\
\hline \multirow{2}{*}{ Model 3} & Boys & -2.87 & $(-6.37,0.62)$ & 0.107 & -7.77 & $\begin{array}{l}(-12.72 \\
-2.81)\end{array}$ & 0.002 \\
\hline & Girls & 1.29 & $(-1.63,4.21)$ & 0.388 & -0.93 & $(-5.22,3.37)$ & 0.672 \\
\hline
\end{tabular}

a In all models, total fluid consumption was treated as the independent variable and the sodium or salt intake was treated as the dependent variable. ${ }^{b} \beta$ represents the partial correlation coefficients in the model, which means the amount of total fluid consumed for each additional $390 \mathrm{mg}$ sodium or $1 \mathrm{~g}$ salt intake. ${ }^{\mathrm{c}}$ Model 1: Adjusted by age and sex; Model 2: Model 1 further adjusted by yearly household income (categorical variable) and maternal education (continuous variable); Model 3: Model 2 further adjusted by intentional physical exercise (categorical variable) and number of instances of eating out last week (categorical variable).

\section{Discussion}

In this study, we found that dietary sodium intake was positively associated with SSB consumption among the study children and adolescents, but dietary salt intake was not. Though dietary sodium and salt were significantly correlated with each other in our results, the two exhibited different associations with SSB consumption. For instance, though it is generally known that Chinese people consume a considerable amount of dietary salt [10], and though previous studies showed that dietary salt was associated with the consumption of SSBs in Western countries $[17,22]$, salt was found to contribute less than two-thirds of dietary sodium in the current participants, which is in line with the finding of a previous study that showed that salt contributed approximately two-thirds of Chinese people's sodium intake [11]. So, the current participants were recruited in Shanghai, a southern metropolis in China where salty sauces are commonly used in food preparation, but their salt intake might not give a complete picture of their overall sodium intake, e.g., due to salty seasonings, such as soy sauce, applied to their food. This might explain why no association was found between dietary salt and SSB consumption in the current study. As such, this study indicates that health promotion in China should not only focus on the 
salt intake but also on the total sodium intake, especially with regard to salty seasonings, which contribute a considerable part of people's dietary sodium.

Compared with studies on Western children, the absolute additional SSB consumption for each $390 \mathrm{mg} / \mathrm{d}$ of dietary sodium intake was not remarkable in the current study. This could be attributed to Chinese children's absolute SSB consumption remaining lower, at present, than that of their Western counterparts [6,23]. Yet, the finding is far from a relief, as based on the trends of Western countries, the SSB consumption is expected to continue to steadily rise among Chinese children, and the adverse effects of that should never be underestimated. Moreover, children are in critical period of taste formation that could last for their whole life [24], and a tendency to enjoy heavy tastes of salty and sweet flavors is not favorable for health maintenance.

When the participants were stratified by school grades, we discovered that the dietary sodium intake, as well as the salt intake, was significantly positively associated with SSB consumption among children in grades 1-5 (6-10 y) but not those in the senior grades. Our findings coincide with the understanding that the linkage between dietary sodium and SSB consumption is significant at a young age but not in adulthood [25]. As such, young children are more vulnerable to the adverse consequences of SSB overconsumption [26]. With that in mind, we propose that they should be the first priority of health promotions targeting SSB or salt reduction among the general population.

When stratified by sex, the dietary sodium intake was associated with SSB consumption among the girls but not the boys in our study, though it was reported that sweet and salty taste preferences were positively correlated among all the children [27]. Since boys usually consumed more SSBs than the girls did [6], we speculate that the desire for SSBs among boys may stem, at least in part, from non-dietary factors such as sense of identity, while girls may consume SSBs more due to a taste desire after salty food intake. This might explain the sex difference found in the association between SSB consumption and sodium intake.

Further to this, we found that dietary sodium and salt were differently associated with the total fluid consumption. The dietary sodium intake was not associated with the total fluid consumption, but the salt intake was negatively associated with total fluid consumption in our participants. This was the opposite finding to previous studies that suggested dietary sodium was positively correlated with the total fluid consumption [17]. Yet, the absolute difference was not that notable in the current results, i.e., a difference of $1 \mathrm{~g}$ salt intake was only related to a difference of $4 \mathrm{~mL}$ in total fluid consumption. We suggest that, as mentioned above, the salt intake might not fully represent the sodium intake since more than one-thirds of the dietary sodium originated from sources other than salt in the current study population. For that reason, we are inclined to take the relationship of dietary sodium with total fluid consumption into account (i.e., no association), rather than the association between the dietary salt intake and total fluid consumption.

One limitation of this study was the methodology used to assess the food and beverage consumption. A dietary record was collected to determine the food and beverage consumption of each participant. In this way, the food name and consumed amount were self-reported by the participants; thus, the food consumption was limited by the accuracy of participants' estimation and recall. Furthermore, although we adjusted for several potential confounding factors, we did not include other unknown confounders that might have caused bias in the current results. Finally, it is logical to hypothesize that excessive sodium intake triggers the desire for sweet beverages, but the cross-sectional nature of the current study did not allow us to infer causal associations. 


\section{Conclusions}

The dietary sodium intake was associated with SSB consumption in Chinese children and adolescents, particularly in young children. The total dietary sodium intake was found to be a more objective factor to focus on than the salt intake only in health promotions. We propose that since the relationship between the dietary sodium intake and SSB consumption, a reduction of the sodium intake might reduce SSB consumption among children and adolescents.

Author Contributions: Z.Z. conceived and designed the experiments; Z.S. and Z.W. performed the field work; J.Z. and Z.W. analyzed the data; J.F. and X.W. interpreted the statistical results; X.C. and X.C. wrote the draft paper; Z.Z. wrote the paper and the final version of the manuscript; Z.Z. supervised the study. All authors have read and agreed to the published version of the manuscript.

Funding: This study was funded by the Study of Diet and Nutrition Assessment and Intervention Technology (no. 2020YFC2006300), part of the Active Health and Aging Technological Solutions Major Project of the National Key R\&D Program-Intervention Strategies for the Main Nutrition Problems in China (no. 2020YFC2006305); Shanghai Municipal Health Commission-Academic Leader Program (GWV-10.2-XD12); the Foundation of Shanghai Municipal Health Commission (201740073), and the Youth Nutrition Elite Development Program of the Chinese Nutrition Society.

Institutional Review Board Statement: The study was conducted in accordance with the Declaration of Helsinki, and the protocol was approved by the Shanghai Municipal Center for Disease Control on 2 September 2015 (no. 2015-15).

Informed Consent Statement: Informed consent was obtained from all subjects involved in the study.

Data Availability Statement: The datasets used and analyzed in the current study are available from the corresponding author on reasonable request.

Acknowledgments: We are grateful to all the individuals who participated in this study. We also thank the teachers from the participating schools as well as the public health doctors at the local districts' Centers for Disease Control and Prevention and at the local community health centers for their assistance with the fieldwork and data collection.

Conflicts of Interest: The authors declare no conflict of interest. The funding sponsors played no role in the design of the study; in the collection, analysis, or interpretation of data; in the writing of the manuscript, or in the decision to publish the results.

\section{Abbreviations}

SSB: sugar-sweetened beverage; $95 \% \mathrm{CI}$, $95 \%$ confidence interval; WHO, World Health Organization; SDHS, Shanghai Diet and Health Survey; CNY, Chinese yuan (China's currency).

\section{References}

1. Wu, Y.; Luo, Y. Time Trends and Socio-demographic Differences in Chinese Children's Sugar-sweetened Beverage Consumption (P18-111-19). Curr. Dev. Nutr. 2019, 3, nzz039-P18. [CrossRef]

2. Kit, B.K.; Fakhouri, T.H.; Park, S.; Nielsen, S.J.; Ogden, C.L. Trends in sugar-sweetened beverage consumption among youth and adults in the United States: 1999-2010. Am. J. Clin. Nutr. 2013, 98, 180-188. [CrossRef] [PubMed]

3. Yu, P.; Chen, Y.; Zhao, A.; Bai, Y.; Zheng, Y.; Zhao, W.; Zhang, Y. Consumption of sugar-sweetened beverages and its association with overweight among young children from China. Public Health Nutr. 2016, 19, 2336-2346. [CrossRef] [PubMed]

4. Ludwig, D.S.; Peterson, K.E.; Gortmaker, S.L. Relation between consumption of sugar-sweetened drinks and childhood obesity: A prospective, observational analysis. Lancet 2001, 357, 505-508. [CrossRef]

5. Li, M.; Li, X.; Zhao, Y.; Zhang, L.; Yang, J.; Zhou, M.; Wang, Z. The burden of ischemic heart disease and type 2 diabetes mellitus attributable to diet high in sugar-sweetened beverages in China: An analysis for the Global Burden of Disease Study 2017. J. Diabetes. 2020, 13, 482-493. [CrossRef] [PubMed]

6. Zhu, Z.; He, Y.; Wang, Z.; He, X.; Zang, J.; Guo, C.; Jia, X.; Ren, Y.; Shan, C.; Sun, J.; et al. The associations between sugarsweetened beverage intake and cardiometabolic risks in Chinese children and adolescents. Pediatr Obes. 2020, 15, e12634. [CrossRef] [PubMed]

7. Bleich, S.N.; Vercammen, K.A. The negative impact of sugar-sweetened beverages on children's health: An update of the literature. BMC Obes. 2018, 5, 6. [CrossRef] [PubMed] 
8. He, B.; Long, W.; Li, X.; Yang, W.; Chen, Y.; Zhu, Y. Sugar-Sweetened beverages consumption positively associated with the risks of obesity and hypertriglyceridemia among children aged 7-18 years in south China. J. Atheroscler. Thromb. 2018, 25, 81-89. [CrossRef]

9. WHO. Guideline: Sodium Intake for Adults and Children; World Health Organization: Geneva, Switzerland, 2012.

10. Hipgrave, D.B.; Chang, S.; Li, X.; Wu, Y. Salt and sodium intake in China. JAMA 2016, 315, 703-705. [CrossRef]

11. Fang, K.; He, Y.; Fang, Y.; Lian, Y. Dietary Sodium Intake and Food Sources among Chinese Adults: Data from the CNNHS 2010-2012. Nutrients 2020, 12, 453. [CrossRef] [PubMed]

12. Anderson, C.A.M.; Appel, L.J.; Okuda, N.; Brown, I.J.; Chan, Q.; Zhao, L.; Ueshima, H.; Kesteloot, H.; Miura, K.; Curb, J.D.; et al. Dietary sources of sodium in china, japan, the United Kingdom, and the United States, women and men aged 40 to 59 years: The INTERMAP study. J. Am. Diet. Assoc. 2010, 110, 736-745. [CrossRef]

13. Leyvraz, M.; Chatelan, A.; da Costa, B.R.; Taffé, P.; Paradis, G.; Bovet, P.; Bochud, M.; Chiolero, A. Sodium intake and blood pressure in children and adolescents: A systematic review and meta-analysis of experimental and observational studies. Int. J. Epidemiol. 2018, 47, 1796-1810. [CrossRef] [PubMed]

14. Grillo, A.; Salvi, L.; Coruzzi, P.; Salvi, P.; Parati, G. Sodium intake and hypertension. Nutrients 2019, 11, 1970. [CrossRef] [PubMed]

15. He, F.J.; Markandu, N.D.; Sagnella, G.A.; MacGregor, G.A. Effect of salt intake on renal excretion of water in humans. Hypertension 1979 2001, 38, 317-320. [CrossRef]

16. Grimes, C.A.; Riddell, L.J.; Campbell, K.J.; Nowson, C.A. Dietary salt intake, sugar-sweetened beverage consumption, and obesity risk. Pediatrics 2013, 131, 14. [CrossRef]

17. Grimes, C.A.; Wright, J.D.; Liu, K.; Nowson, C.A.; Loria, C.M. Dietary sodium intake is associated with total fluid and sugarsweetened beverage consumption in US children and adolescents aged 2-18 y: NHANES 2005-2008. Am. J. Clin. Nutr. 2013, 98, 189-196. [CrossRef] [PubMed]

18. Greenhalgh, S. Making China safe for Coke: How Coca-Cola shaped obesity science and policy in China. BMJ. 2019, 364, k5050. [CrossRef]

19. Human experimentation: Code of ethics of the world medical association (Declaration of helsinki). Can. Med. Assoc. J. 1964, 91,619 .

20. Yang, Y.; Wang, G.; Pan, X. Chinese Food Composition Book 1; Peking University Medical Press: Beijing, China, 2009; pp. 45-192, ISBN 9787811167276.

21. Yang, Y.; Wang, G.; Pan, X. Chinese Food Composition Book 2; Peking University Medical Press: Beijing, China, 2005; pp. 75-216, ISBN 9787810716789.

22. He, F.J.; MacGregor, G.A. Salt intake, sugar-sweetened soft drink consumption, and blood pressure. Am. J. Cardiol. 2014, 114, 499-500. [CrossRef]

23. Rosinger, A.; Herrick, K.; Gahche, J.; Park, S. Sugar-sweetened Beverage Consumption among U.S. Youth, 2011-2014. NCHS Data Brief 2017, 271, 1-8.

24. Daniel, C. Economic constraints on taste formation and the true cost of healthy eating. Soc. Sci. Med. 1982 2016, 148, 34-41. [CrossRef] [PubMed]

25. Grimes, C.A.; Bolton, K.A.; Booth, A.B.; Khokhar, D.; Service, C.; He, F.H.; Nowson, C.A. The association between dietary sodium intake, adiposity and sugar-sweetened beverages in children and adults: A systematic review and meta-analysis. Brit. J. Nutr. 2020, 126, 409-427. [CrossRef] [PubMed]

26. Okubo, H.; Miyake, Y.; Sasaki, S.; Tanaka, K.; Hirota, Y. Early sugar-sweetened beverage consumption frequency is associated with poor quality of later food and nutrient intake patterns among Japanese young children: The Osaka Maternal and Child Health Study. Nutr. Res. 2016, 36, 594-602. [CrossRef] [PubMed]

27. Mennella, J.A.; Finkbeiner, S.; Lipchock, S.V.; Hwang, L.; Reed, D.R.; Meyerhof, W. Preferences for salty and sweet tastes are elevated and related to each other during childhood. PLoS ONE 2014, 9, e92201. [CrossRef] 